\title{
Erratum to: The impact of hydrophobic hernia mesh coating by omega fatty acid on atraumatic fibrin sealant fixation
}

\author{
S. Gruber-Blum $\cdot$ J. Brand $\cdot$ C. Keibl $\cdot$ H. Redl $\cdot$ \\ R. H. Fortelny $\cdot$ C. May $\cdot$ A. H. Petter-Puchner
}

Published online: 20 February 2015

(c) Springer-Verlag France 2015

\section{Erratum to: Hernia}

\section{DOI 10.1007/s10029-014-1304-y}

The authors would like to notify readers that unfortunately, Fig. 1 and associated captions are incorrectly published in the original publication. The correct figure and legend are given here:

The online version of the original article can be found under doi:10.1007/s10029-014-1304-y.

S. Gruber-Blum · C. Keibl · H. Redl ·

A. H. Petter-Puchner $(\square)$

Ludwig Boltzmann Institute for Experimental and Clinical

Traumatology, Cluster for Tissue Regeneration,

Donaueschingenstrasse 13, 1200 Vienna, Austria

e-mail: alexander.petter@trauma.lbg.ac.at

J. Brand

Department of Traumatology, Federal Hospital Horn,

Spitalgasse 10, 3580 Horn, Austria

R. H. Fortelny · C. May · A. H. Petter-Puchner

Department of General, Visceral and Oncological Surgery,

Wilhelminenspital, Montleartstrasse 37, 1171 Vienna, Austria

R. H. Fortelny

Paracelsus Medizinische Privatuniversität, Strubergasse 21,

5020 Salzburg, Austria 


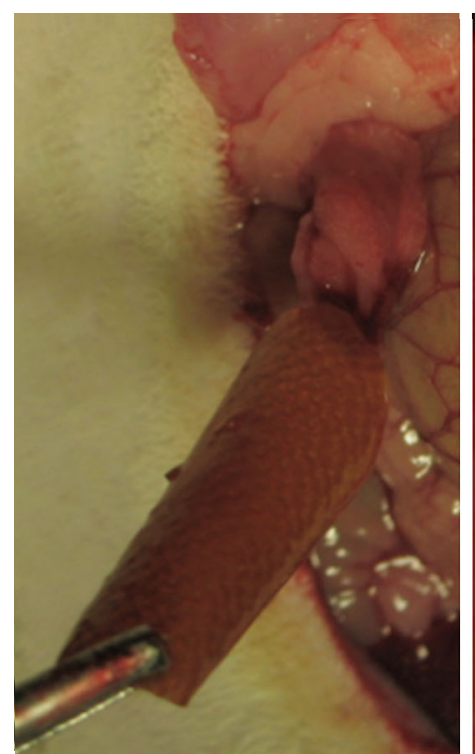

Fig. 1 Fibrin sealant- versus suture fixation in the IPOM position at 6 weeks follow-up. The sealed mesh (left picture) is not adherent to the abdominal wall. Asterisks mark incomplete tissue integration of

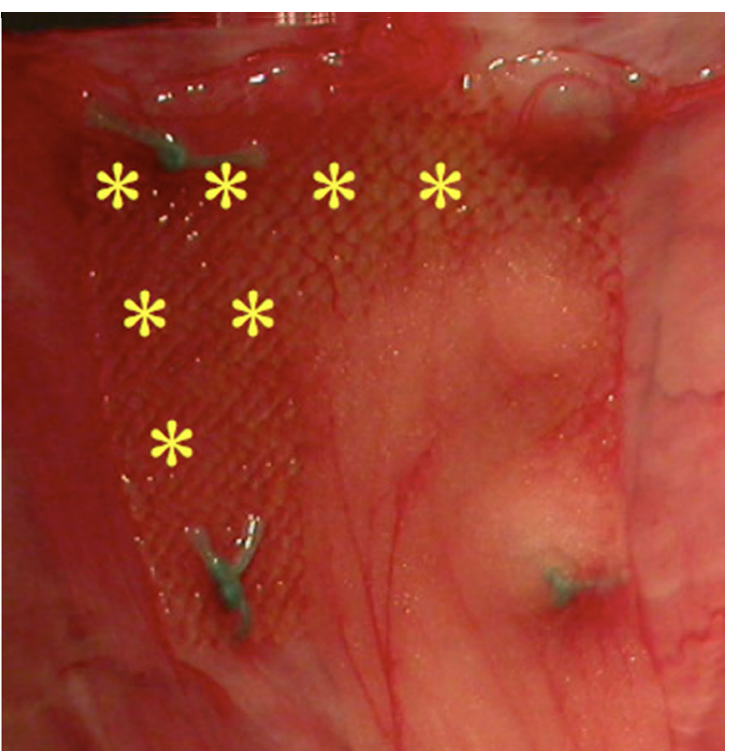

mesh margins and surface in the sutured implant. Adhesion strands are mainly covering sutures and mesh borders 